\title{
LA PROMOCIÓ DE LA LECTURA A LES BIBLIOTEQUES PÚBLIQUES DE CATALUNYA (2018-2019)
}

LA PROMOCIÓN DE LA LECTURA EN LAS BIBLIOTECAS PÚBLICAS DE CATALUÑA (2018-2019)

THE PROMOTION OF READING AT PUBLIC LIBRARIES IN CATALONIA (2018-2019) 


\section{RESUM | RESUMEN | ABSTRACT}

Durant el període 2018-2019, es desenvolupa, progressivament, un canvi de model de biblioteca pública a Catalunya, basat en la creació de coneixements i la innovació ciutadana, en què destaquen les activitats de descoberta i experimentació. En aquest model, la participació ciutadana i el factor tecnològic tenen un paper important. L'article recull una selecció de programes, accions i serveis que han dut a terme les biblioteques públiques catalanes, principalment en l'àmbit de la promoció i el foment de la lectura. També se citen les jornades i trobades professionals més destacades, així com els premis, estudis de recerca i les publicacions principals sobre la matèria que s'han publicat en aquest bienni.

Durante el periodo 2018-2019, se desarrolla, progresivamente, un cambio de modelo de biblioteca pública en Cataluña, basado en la creación de conocimientos y la innovación ciudadana y en el que destacan las actividades de descubrimiento y experimentación. En este modelo, la participación ciudadana y el factor tecnológico tienen un papel importante. El artículo recoge una selección de programas, acciones y servicios que han llevado a cabo las bibliotecas públicas catalanas, principalmente en el ámbito de la promoción y el fomento de la lectura. También se comentan las jornadas y encuentros profesionales más destacadas, así como los premios, estudios de investigación y las publicaciones principales sobre la materia que se han publicado en este bienio.

In 2018-2019, a change in the public library model in Catalonia was progressively introduced, based on the creation of knowledge and citizen-driven innovation. Programmes of exploration and experimentation, citizen participation, and technology are the key features of this model. This paper describes a selection of the activities and services offered in Catalan public libraries, particularly in relation to the promotion of reading. Talks by experts, meetings, awards, research studies, and the most important publications published during this two-year period are also included.

PARAULES CLAU:

Promoció de la lectura, Biblioteques públiques catalanes, Xarxes de biblioteques

PALABRAS CLAVE:

Promoción de la lectura, Bibliotecas públicas catalanas, Redes de bibliotecas

Reading promotion, Catalan public libraries, Library networks 


\section{PRESENTACIÓ}

En l'article següent es repassen les principals accions al voltant de la promoció $\mathrm{i}$ el foment de la lectura dutes a terme a les biblioteques públiques catalanes els anys 2018 i 2019, un bienni marcat pel canvi de model bibliotecari que està experimentant el nostre territori, en què guanyen importància les activitats de descoberta, creació i generació de nous continguts i coneixements.

Aquesta nova realitat dels equipaments bibliotecaris ha comportat un increment en el nombre d'activitats dutes a terme respecte dels darrers anys $i$ en el nombre de participants. Malgrat això, en aquest article ens centrarem, principalment, en les activitats que tenen la promoció i la creació de l'hàbit lector i la difusió de la literatura com a objectius principals.

\section{LA PROMOCIÓ DE LA LECTURA A LES BIBLIOTEQUES PÚBLIQUES}

\subsection{Accions d'àmbit nacional}

Durant el 2018, els quatre-cents setze equipaments (quatre-centes quatre biblioteques i dotze bibliobusos) integrants del Sistema de Lectura Pública de Catalunya van rebre més de 24,5 milions de visites i van prestar 13,5 milions de documents. Es van organitzar 73.946 sessions d'activitats de foment de la lectura a les biblioteques amb 1.534 .740 assistents en total. Pel que fa al 2019, les biblioteques catalanes van rebre vint-i-cinc milions de visites i van organitzar unes 76.948 sessions d'activitats amb uns 1.575 .050 participants.

El Servei de Biblioteques de la Generalitat de Catalunya ha impulsat una gran quantitat de projectes al voltant de la promoció de la lectura i la cultura. Els projectes que es consoliden són els següents:

- Biblioteques amb DO. Projecte que porta la cultura del vi a les biblioteques públiques de Catalunya. A través de les denominacions d'origen vitivinícoles, les biblioteques es reivindiquen com a dinamitzadores culturals del territori, reforçant els recursos informatius sobre la temàtica $\mathrm{i}$ oferint un extens programa d'activitats. El 2018 en el projecte hi van participar seixanta-sis
En aquest bienni

guanyen

importància les

activitats de

descoberta, creació i

generació de nous

continguts $i$

coneixements 
biblioteques i el 2019 va augmentar fins a les setanta biblioteques participants.

- Llegir el Teatre. El club de lectura de textos teatrals en col·laboració amb el Teatre Nacional de Catalunya arriba a la sisena edició el curs 2018-2019 amb la participació de cent setze biblioteques públiques i gairebé 2.300 lectors i lectores, mentre que el 2017-2018 van ser cent biblioteques i 1.980 usuaris.

- Balla'm un Llibre. Cicle de coreografies curtes basades en textos literaris per ser interpretats dins les biblioteques amb l'objectiu d'apropar el llenguatge coreogràfic a tots els públics. Col-laboració entre l'Associació de Professionals de la Dansa de Catalunya (APdC), I'Institut Català de les Empreses Culturals i el Servei de Biblioteques del Departament de Cultura. El 2018, la quarta edició va incloure quatre espectacles i la participació de dotze biblioteques. El 2019 s'amplia l'extensió i l'impacte del programa amb cinc espectacles i vint-i-una biblioteques participants.

- Concurs de Bibliotràilers. Des del 2013 el Servei de Biblioteques del Departament de Cultura de la Generalitat de Catalunya i la Universitat Oberta de Catalunya (UOC) convoquen un concurs de bibliotràilers adreçat a joves de dotze a divuit anys amb l'objectiu de dinamitzar i promoure la lectura mitjançant la creació audiovisual. El 2018 s'hi van presentar un total de cent vint bibliotràilers fets per més de quatre-cents joves. El 2019 la xifra de bibliotràilers va augmentar a cent vuitanta vídeos presentats per més de cinc-cents joves.

- LiceuBib. Projecte que promou els clubs de lectura i audició d'òpera a les biblioteques públiques catalanes amb la col·laboració del Gran Teatre del Liceu. En la temporada 2018-2019 hi van participar quaranta-tres biblioteques i 1.182 usuaris i la temporada 20192020, vint-i-quatre biblioteques i 791 usuaris.

Els projectes nous de promoció de la lectura han estat els següents:

- Supernit. Organitzada pel Club Super3 i el Departament de Cultura de la Generalitat de Catalunya, la Supernit té per objectiu promoure la lectura i les biblioteques públiques, introduint la figura del llibre en les històries televisives dirigides al públic infantil. Es tracta d'una activitat multitudinària, simultània i transmèdia per tot el territori amb un gran èxit d'assistència. El 2018 hi van participar unes 274 biblioteques amb uns quinze mil infants i les seves famílies, i el 2019, dues-centes setanta biblioteques amb uns divuit mil participants.

- Lectures en Ruta. És un projecte d'immersió literària adreçat a joves de divuit a vint-i-cinc anys que convida a descobrir i compartir inquietuds lectores a través d'un recorregut per tot Catalunya tot
El Servei de

Biblioteques de la Generalitat de

Catalunya ha

impulsat una gran

quantitat de

projectes al voltant

de la promoció de la

lectura i la cultura 
descobrint alguns dels seus paisatges més literaris, amb tallers i activitats a càrrec d'escriptors, editors $\mathrm{i}$ altres protagonistes del món de la literatura més actual. El Servei de Biblioteques en col-laboració amb la Institució de les Lletres Catalanes i Tramoia Produccions Culturals va fer una primera edició el 2019.

- Petit LiceuBIB. Novetat iniciada el 2019 dins del programa ja consolidat LiceuBIB. Un mínim de dotze biblioteques catalanes han organitzat sessions de dinamització i àudio destinades a públic familiar a partir del programa Petit Liceu.

\subsection{Accions d'àmbit regional}

A la província de Barcelona destaquen els projectes impulsats per la Gerència del Servei de Biblioteques de la Diputació de Barcelona que es desenvolupen a la Xarxa de Biblioteques Municipals:

- Debat a Bat. Es consolida el projecte i es presenta al festival Kosmopolis 2019 (CCCB). També s'ha identificat com un projecte de referència a la plataforma digital de bones pràctiques literàries amb públic jove del projecte europeu Engage! liderat pel PEN Català. El 2018, es van fer cent tretze sessions a trenta-una biblioteques i s'hi van incorporar dotze biblioteques noves. El 2019, hi van participar cinquanta-nou biblioteques i se n'hi van incorporar nou de noves.

- Bibliolab. En l'àmbit del foment de la lectura destaquen la «Residència d'art digital i oralitat» $\mathrm{i}$ «Read on». La «Residència d'art digital i oralitat» es duu a terme a les biblioteques de Gavà en col·laboració amb Tantàgora i s'adreça a artistes de la paraula, creadors digitals i tecnològics per desenvolupar projectes de recerca o producció artística sobre noves oralitats digitals. "Read on» és un projecte de participació collectiva, que promou trobades de la creació i la innovació en l'àmbit de la literatura i s'adreça a joves de dotze a divuit anys. Es desenvolupa gràcies a la col-laboració de la Gerència del Servei de Biblioteques, l'Àrea d’Educació de la Diputació de Barcelona i Tantàgora. El 2019, hi van participar setanta-cinc joves biblioteques i instituts de Sant Feliu de Codines, Cardedeu i Sabadell.

- Jo Llegeixo (2019). Projecte de promoció de la lectura entre els alumnes d'institut d'onze municipis, desenvolupat conjuntament entre la Gerència del Servei de Biblioteques i la Gerència del Servei d'Educació (DIBA). Hi han participat deu biblioteques que han rebut vuit lots de quaranta títols i s'han repartit 979 llicències digitals per fer el seguiment de les lectures a través d'una plataforma digital.

Continuen projectes ja consolidats com els Laboratoris portàtils de lectura, amb més de noranta biblioteques de cinquanta-vuit municipis de la
A la província de

Barcelona

destaquen els

projectes impulsats

per la Gerència del

Servei de

Biblioteques de la

Diputació de

Barcelona 
província o el Club del llibre amb una mitjana de divuit trobades anuals, trenta-tres autors diferents i 3.804 participants.

- Bibliobusos. Es consolida l'aposta per les activitats adreçades als infants amb una tendència a l'alça en nombre d'activitats $i$ assistents (2018: cent vuitanta-quatre activitats amb 14.469 assistents; 2019: cent noranta-nou activitats amb 15.693 assistents). El 2019 s'inicia un projecte pilot d'activitats adreçades al públic adult («Club del llibre, Projecte Liceu: xerrades i assistència a l'òpera»).

Durant el 2018, a la Xarxa de Biblioteques Municipals van programar un total de 42.461 activitats amb 787.542 participants, i el 2019, 41.913 activitats amb 777.220.

A la demarcació de Girona, els projectes regionals desenvolupats en aquest bienni han estat:

- Bibliomakers. Projecte gestionat pel Servei de Biblioteques de Girona i elaborat per Innova't Educació amb l'objectiu de dotar d'un espai tecnològic i flexible les biblioteques gironines. En aquest espai, es busca que infants $i$ joves es puguin reunir per dissenyar $i$ construir alguna cosa tangible, digital o física, partint de les seves idees prèvies, compartint recursos i coneixements de manera collaborativa. $\mathrm{Hi}$ ha tres tipus de tallers: robòtica, realitat augmentada i creació de videojocs.

- Un Llibre, un Destí. Projecte engegat el 2019 pel Servei de Biblioteques de la Diputació de Girona que consisteix en una gran trobada de clubs de lectura en una localitat gironina relacionada directament amb una novel.la. A la primera edició, el llibre escollit ha estat El fill de l'italià, de Rafel Nadal, i el municipi, Caldes de Malavella. A l'activitat van assistir-hi dos-cents participants de setze biblioteques de la demarcació.

- Activa la Llengua. Projecte que, amb la collaboració de les biblioteques de les comarques de Girona i el Centre de Normalització Lingüística de Girona, ofereix un punt de trobada per dur a terme activitats culturals i formatives per als alumnes de cursos de català $\mathrm{i}$ per a les persones voluntàries del programa Voluntariat per la Llengua ( $\mathrm{VxL})$.

A la demarcació de Lleida, els projectes regionals s'han centrat en:

- Tarter de Llibres. És un projecte de les biblioteques dels Pallars i l'Alta Ribagorça per promocionar el patrimoni literari, musical i fílmic del seu territori. Aquesta difusió del fons local es fa principalment a partir d'un bloc i d'un compte de Twitter. També s'hi emmarquen accions com "El joc de l'estiu», un concurs per promocionar els autors i autores locals.
Bibliomakers és un projecte gestionat pel Servei de

Biblioteques de Girona amb l'objectiu de dotar d'un espai tecnològic i flexible les biblioteques gironines 
- Llegeix que fa Fort: 'Tiros' i Crims. Catorze biblioteques de la demarcació han participat en el projecte que consisteix en la dinamització conjunta de dues exposicions "Un disparo al autor», de la fotògrafa Ana Portnoy, i «S'ha escrit un crim», produïda pel Consell Català del Llibre Infantil i Juvenil (ClijCat); l'organització de clubs de lectura temàtics de novel-la policíaca; la proposta de lectures d'una sèrie de títols d'autors $i$ autores de gènere negre; xerrades, i presentacions de llibres.

- Any Pedrolo i Any Pàmies. Entorn de les celebracions de l'Any Manuel de Pedrolo el 2018 i l'Any Teresa Pàmies el 2019, la Central de Biblioteques de Lleida ha organitzat un programa d'activitats a més de vint-i-tres biblioteques de Ponent, el Pirineu i l'Aran. Les accions dutes a terme en els dos casos han previst la itinerància d'exposicions, la lectura de l'obra de Pedrolo i Pàmies als clubs de lectura, conferències, concerts i xerrades al voltant dels autors i la seva obra, i sortides per visitar espais literaris directament relacionats amb ells.

Els projectes més destacats de les biblioteques de la demarcació de Tarragona han estat:

- Píndoles de Salut. Proposta de renovació del fons de salut de les biblioteques del territori acompanyada d'un cicle d'activitats, clubs de lectura, tallers i xerrades temàtiques de professionals de l'àmbit sanitari i amb experiència en la divulgació científica. El projecte s'ha desenvolupat el $2018 \mathrm{i}$ els àmbits temàtics treballats principalment han estat la nutrició i l'alimentació, la bellesa i la salut, la gent gran i l'envelliment actiu, i les malalties i la seva prevenció.

- Arriben els Bandolers. Cicle d'activitats per a l'estiu del 2018 per conèixer les petjades dels bandolers al territori tarragoní. L'objectiu és presentar d'una manera lúdica el fons de les biblioteques d'història, geografia $i$ altres documents relacionats amb els paisatges, les llegendes i els contes sobre un tema que encara avui perdura.

- ArTer, Art i Artistes del Territori. Es tracta d'un projecte creat el 2019 que pretén donar a conèixer l'obra i el treball dels artistes més internacionals vinculats a la província (Antoni Gaudí, Joan Miró, Josep M. Jujol, Pau Casals, etc.), així com posar en valor l'art i el patrimoni des de les biblioteques públiques. El programa s'articula a través de tot un conjunt d'activitats i propostes culturals i disposa del recurs l' "Aparador de llibres d'art», un lot de llibres d'artista itinerant entre les biblioteques que es posa a disposició per fer aparadors culturals.

El projecte comunitari més destacat a les Terres de l'Ebre és Biblioteques i Salut Mental, que es consolida el 2018. Impulsat per la Central de
Tarter de Llibres és un projecte de les biblioteques dels Pallars i l'Alta Ribagorça per promocionar el patrimoni literari, musical i fílmic del seu territori

Píndoles de Salut és una proposta de renovació del fons de salut de les biblioteques de Tarragona acompanyada d'un cicle d'activitats on participen professionals de l'àmbit sanitari i amb experiència en la divulgació científica

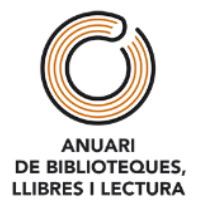


Biblioteques de les Terres de l'Ebre en col-laboració amb l'Institut de Salut Mental Pere Mata d'Amposta i els Serveis Territorials de Cultura a les Terres de l'Ebre, dona visibilitat als malalts mentals amb accions que es desenvolupen a les biblioteques públiques del territori. Durant els anys 2018-2019 s'han dut a terme cent cinquanta activitats amb 4.544 participants a divuit biblioteques diferents.

\subsection{Accions d'àmbit municipal}

Hi ha una quantitat immensa de propostes i projectes de promoció de la lectura destacables a les biblioteques públiques catalanes, de manera que en recollim algunes que sobresurten per l'originalitat o impacte, per bé que la llista podria ser molt més extensa.

A la província de Barcelona, tenim el cicle mensual d'activitats «12 mesos, 12 rondalles» impulsat per la Biblioteca Infantil i Juvenil Can Butjosa de Parets del Vallès, dedicat a les rondalles populars per donar a conèixer les versions originals, així com la visió que hi aporten l'antropologia, la psicologia, la filosofia, la filologia, etc. De manera col-lectiva, el grup de treball Comissió Jove de la zona del Vallès Oriental I promou «El plaer de les lectures obligatòries a batxillerat», unes experiències vivencials que apropen les lectures obligatòries de batxillerat als alumnes de manera amena i experimental. Han desenvolupat tres visites per Terra Baixa, Mirall trencat i Luces de Bohemia que s'han dut a terme a la Biblioteca Municipal de Ripollet, la Biblioteca Sud de Sabadell i a la Biblioteca Elisenda de Montcada durant els anys 2018 i 2019. Submerllibres, de la Biblioteca Santa Oliva d'Olesa de Montserrat, és un joc de pistes literari amb realitat augmentada desenvolupat durant la Setmana de la Ciència del 2018, entre la Biblioteca, el Centre de Visió per Computador, dues companyies de teatre professional, dos directors de cinema olesans i tres actors locals.

El Consorci de Biblioteques de Barcelona ha dut a terme el programa de promoció de la lectura Velocirepte durant el 2018. L'objectiu de la proposta és atreure els usuaris i usuàries a propostes lectores no habituals, reptant cada mes a llegir un llibre d'una temàtica concreta (Àfrica no és un país; dones que trenquen esquemes, etc.). A la proposta hi ha participat 3.524 usuaris.

Les iniciatives d'àmbit municipal de les biblioteques de la província de Girona destaquen per la seva consolidació. En trobem moltes amb una llarga trajectòria i evolució, com ara el concurs Bolleré de relats breus per a joves que va començar l'any 2006 i que es manté viu (el 2018 se'n celebra la desena edició i el 2019, l'onzena) o el Programa de Biblioteques Escolars de la ciutat de Girona, que es va iniciar l'any 2011 fruit d'una iniciativa de les biblioteques públiques i l'Ajuntament, i que ofereix assessorament, formació i aportació econòmica a quaranta-dos centres educatius. Com a novetat destaca Rius de Llibres, un servei d'extensió bibliotecària impulsat per Biblioteques de Girona en colllaboració amb l'espai de recollida i distribució de llibres usats Connexió Papyrus que posa a disposició de tota
Biblioteques i Salut

Mental és un

projecte impulsat

per la Central de

Biblioteques de les

Terres de l'Ebre amb

l'objectiu de donar

visibilitat als malalts

mentals amb

accions que es

desenvolupen a les

biblioteques

públiques del

territori 
la població llibres de segona mà en prestatgeries instal-lades en espais públics de la ciutat.

Dins els projectes municipals de promoció de la lectura destacats de la província de Lleida trobem el Mes de la Poesia als Comerços, de la Biblioteca Carles Morató de Solsona, emmarcat el març dins el Dia Mundial de la Poesia, o el projecte Bibliocursa, per fomentar la lectura entre els usuaris de nou a onze anys de la Biblioteca Marquès d'Olivart de les Borges Blanques. També cal destacar el programa d'activitats municipals de la Biblioteca Margarida de Montferrat de Balaguer dins l'Any Teresa Pàmies incloent-hi la creació de la ruta literària "Balaguer i Teresa Pàmies». A mig camí entre el club de lectura i el taller d'escriptura creativa el projecte Lletres Rebels, en què la Biblioteca Carles Morató de Solsona col·labora, vol posar en valor la mirada i la veu de les dones a través de la literatura.

Entre els projectes de Tarragona, trobem el Banc de la Salut, un projecte transversal d'un grup de treball interdisciplinari del qual la Biblioteca Mestra Maria Antònia de Torredembarra forma part amb altres agents de salut del territori, que té per objectiu millorar la salut comunitària per reduir la medicació i prescriure cultura, esport, socialització, art, etc. La Biblioteca acull les reunions i ha ajudat a la creació de la xarxa i de l'emblema (el banc blau inspirat en el llibre d'Albert Asensio). La Biblioteca Pública de Tarragona i el Servei de Joventut de l'Ajuntament, en col-laboració amb l'Escola de Lletres de Tarragona i la Universitat Rovira i Virgili, impulsen Ciutat a Cau d'Orella, un programa d'activitats d'oci, educatives i de treball comunitari, majoritàriament nocturnes, relacionades amb les llegendes urbanes i els rumors, i dirigides i cocreades amb el públic jove.

A les Terres de l'Ebre, la biblioteca de les Cases d'Alcanar el 2019 va engegar el projecte d'animació a la lectura Llegim Junts, unes trobades mensuals per a infants de set a nou anys on es comparteix un llibre practicant la lectura en veu alta. A Gandesa, la biblioteca va impulsar l'any 2018, el Club Feminista de Lectura, que va tenir una gran acceptació entre la població. De periodicitat bimestral, s'hi llegeixen diferents gèneres, tots amb temàtica feminista, sobre sexualitat i sobre erotisme.

\section{DIFUSIÓ I DIVULGACIÓ}

\subsection{Congressos, seminaris i reunions científiques}

2018

- 15es Jornades Catalanes d'Informació i Documentació. Barcelona, 10 i 11 de maig de 2018

\section{Hi ha una quantitat immensa de \\ propostes i projectes de promoció de la lectura destacables a les biblioteques públiques catalanes}


Trobada organitzada pel Col-legi Oficial de BibliotecarisDocumentalistes de Catalunya, amb el lema «Diversitat de BiDes». Tres eixos temàtics van marcar les sessions de les Jornades: innovadors, singulars i gestors, en les quals es van presentar un bon grapat d'experiències i bones pràctiques al voltant de la promoció de la lectura.

- Extra! Extra! Cicle de trobades amb autors, editors i professionals del món del llibre infantil i juvenil. Barcelona, 24 d'abril de 2018 Trobada amb l'autor i il-lustrador de llibres per a infants Ed Vere, organitzada pel Bib.Botó, Grup de Treball de Biblioteques Infantils i Juvenils; I'Editorial Joventut; la Llibreria Al-lots, i les biblioteques de Barcelona.

- 4a Jornada de Biblioteques de Badalona. Badalona, 26 de juny de 2018

Sota el títol "Llegir per aprendre», aquestes jornades sorgides per iniciativa de la Comissió de Dinamització Lectora de Badalona, tenen per objectiu convertir-se en un espai de debat sobre la lectura com a font de plaer $\mathrm{i}$ sobre les experiències de l'oralitat a partir de la lectura.

- V Jornades de Laboratoris de Lectura. Granollers, 29 i 30 de juny de 2018

«Habitar la imatge. El relat fotogràfic en la literatura per a infants» era el tema central de les Jornades organitzades per la Biblioteca Roca Umbert de Granollers. Pretén endinsar-se en la fotografia i analitzar el seu impacte en els llibres per a infants $i$ joves.

- 9a Escola d'Estiu de Literatura Infantil i Juvenil. Montserrat, 3, 4 i 5 de juliol de 2018

Jornades organitzades per la Universitat de Vic, en col-laboració amb l'Abadia de Montserrat, adreçades a professionals de l'àmbit de l'ensenyament i de la biblioteca infantil. Aquesta edició, sota el lema «Festa, joia i cançó en la literatura infantil i juvenil», les Jornades van centrar-se a reflexionar entorn del valor de la transmissió oral de la literatura per a infants i joves i la seva funció cultural i social.

- Riudelletres. Sant Pere de Riudebitlles, 26 de setembre de 2018 Segona edició de la jornada de treball, debat i formació que vol agrupar tots els sectors implicats en el món de la literatura amb l'objectiu de cercar noves fórmules per a la promoció de la lectura. Les xerrades es van centrar en temes com la comunicació editorial i la prescripció a mitjans i xarxes socials.

- 2a Jornada-Col-loqui Miquel Martí i Pol de literatura i educació. Girona, 24 i 25 de novembre de 2018

Sota el lema "Literatura i educació», la Jornada pretenia donar eines i recursos a professionals en l'àmbit de la literatura, la cultura
Tres eixos temàtics

van marcar les

sessions de les 15 es

Jornades Catalanes

d'Informació i

Documentació:

innovadors,

singulars i gestors

«Habitar la imatge.

El relat fotogràfic en

la literatura per a

infants" era el tema

central de les

Jornades

organitzades per la

Biblioteca Roca

Umbert de

Granollers 
i l'educació perquè poguessin aplicar-los dins i fora dels centres escolars. Sota el paraigües del poeta Miquel Martí i Pol com a referent, la poesia per a infantil i primària va ser el tema central.
- 8a Jornada Biblioteca Pública i Cohesió Social «La participació dels joves a la biblioteca». Barcelona, 8 d'abril de 2019

Jornada biennal que organitza el Consorci de Biblioteques Públiques de Barcelona i que ofereix un seguit d'experiències al voltant d'un eix comú, en aquest cas el tema central van ser els joves, com promoure $\mathrm{i}$ incorporar la seva participació a les biblioteques, a través de la col-lecció, la promoció de la lectura, les activitats culturals i els perfils professionals especialitzats.

- 3a Jornada de Còmic i Biblioteques. L'Hospitalet de Llobregat, 30 de maig de 2019

Trobada al voltant del món del còmic $\mathrm{i}$ les biblioteques que organitzen conjuntament les biblioteques Tecla Sala de Biblioteques de I'Hospitalet i Ignasi Iglésias - Can Fabra de Biblioteques de Barcelona. Aquesta edició es va centrar en la reivindicació de la igualtat de gènere en el còmic $i$ la presència femenina en aquest sector.

- 10a Escola d'Estiu sobre Literatura Infantil i Juvenil. Montserrat, 2, 3 i 4 de juliol de 2019

La Universitat de Vic, en col·laboració amb l'Abadia de Montserrat, organitza aquestes jornades. L'edició del 2019 es va centrar en "Viure la literatura: paraula, ritme i bones històries», tema que permet reflexionar sobre el valor de la vivència literària durant la infància o la joventut i sobre alguns dels elements que fan possible una experiència literària de qualitat en diferents contextos (social, cultural, educatiu, etc.).

- IV Jornada Biblioteca \& Comunitat Educativa. Cornellà de Llobregat, 18 de novembre de 2019

Destinada a professorat, bibliotecaris i referents de biblioteques públiques i escolars, la quarta edició d'aquesta jornada proposa un espai matinal de treball, reflexió i intercanvi a voltant del titular "Complexitat i complicitats», un apropament als aprenentatges que van Iligats directament a la lectura i a l'observació, amb la participació d'Anna Juan, doctora en Antropologia Social i Cultural i màster en Llibres i Literatura Infantil.

- Jornada professional «Noves narratives il-lustrades: el camí entre l'àlbum i els llibres il-lustrats de no-ficción, 23 de febrer de 2019 Jornada professional de la Fira del Llibre Infantil i Juvenil de Montcada i Reixac adreçada a professionals sobre els llibres de coneixements i les noves tendències en l'àlbum.
Els joves van ser el tema central de la $8 a$ Jornada Biblioteca Pública i Cohesió Social

La IV Jornada

Biblioteca \&

Comunitat Educativa

es va centrar en el

titular «Complexitat

i complicitats», un

apropament als

aprenentatges que

van Iligats

directament a la

lectura i a

l'observació 
- Riudelletres. Sant Pere de Riudebitlles, 4 de maig de 2019 La tercera edició de la jornada de treball, debat i formació al voltant de la promoció de la literatura es va centrar en la crítica literària.

- Jornades de Prescripció de Còmic, Manga i Novel·la Gràfica. Barcelona, 18 i 25 de novembre de 2019

La Biblioteca Ignasi Iglésias - Can Fabra de Barcelona, en col-laboració amb ACDCómic, organitza unes jornades dedicades a la prescripció de còmics per a professionals de biblioteques, en què es revisen les novetats del sector.

- 7a Trobada de Lectura Fàcil. Barcelona, 25 de novembre de 2019 L’Associació Lectura Fàcil i la Xarxa de Lectura Fàcil organitzen anualment una trobada amb l'objectiu de fer accessible la lectura, la cultura i la informació a tothom, amb especial atenció a les persones amb dificultats lectores. En aquesta setena edició es va voler donar a conèixer l'evolució de la lectura fàcil a escala nacional i internacional en els darrers anys, i com l'accessibilitat als continguts s'està aplicant en àrees com la cultura o les administracions públiques.

\subsection{Exposicions}

L'exhibició i la instal·lació d'exposicions a les biblioteques públiques és un dels recursos més emprats per promocionar la lectura d'una forma visual i atractiva. Les exposicions que normalment s'allotgen als equipaments bibliotecaris són de muntatge fàcil, els formats més emprats i estesos de les quals són els de banderoles tipus roll-up i els plafons, tot i que els materials i les opcions són infinites (marcs, tòtems de cartró, caixes de fustes, moquetes impreses, etc.).

El 2018 el Servei de Biblioteques de la Generalitat de Catalunya ha fet itinerar una dotzena d'exposicions per cent setanta-quatre biblioteques de tot el territori i per unes vuitanta-cinc el 2019. Per la seva banda, la Gerència del Servei de Biblioteques de la Diputació de Barcelona ha ofert el 2018 i el 2019 una trentena d'exposicions que s'han exhibit a unes duescentes cinquanta biblioteques.

D'entre les exposicions exhibides, en trobem de dedicades al món de la literatura $\mathrm{i}$ de les biblioteques com «Geografies literàries de José Luis Sampedro», «Paisatges literaris», "Catalunya il-lustrada» $i$ «La biblioteca al laberint»; d'altres de relacionades amb les efemèrides i commemoracions anuals: "Teresa Pàmies. Tot és en els llibres», "Amparo Poch y Gascón, el compromís d'una dona lliure», "Brossa polièdric», "Maria Aurèlia Capmany» o "Montserrat Abelló»; exposicions que treballen la literatura infantil com "25 imperdibles», "La carbassa, la poma i el pèsol», "Éssers diminuts fabulosos», "S'ha escrit un crim», "Super Women, Super Inventors» o "Visca la revolució». I, per acabar, exposicions d'altres temàtiques diverses com "Merletti i l'esport al primer terç del segle XX»,

\author{
L'exhibició i la \\ instal·lació \\ d'exposicions a les \\ biblioteques \\ públiques és un dels \\ recursos més \\ emprats per \\ promocionar la \\ lectura d'una forma \\ visual i atractiva
}


«Mira'm. La realitat desconeguda dels joves extutelats» o «Objectius de Desenvolupament Sostenible».

\subsection{Premis}

Durant el període 2018-2019, s'atorguen pocs premis a iniciatives de promoció de la lectura de les biblioteques catalanes, a causa d'una baixa participació.

- Premi Maria Moliner d'animació a la lectura. En la convocatòria del 2018, s'han presentat setze candidatures de biblioteques públiques catalanes, de les quals només s'han premiat cinc:

- Biblioteca Sant Valentí (Navarcles). Iniciativa premiada: "Cinco años de biblioteca, multitud de propuestas para llegar a todos los públicos».

- Biblioteca de Sant Fruitós de Bages. Iniciativa premiada: «Crecer leyendo».

- Biblioteca Mercè Rodoreda (Sant Joan Despí). Iniciativa premiada: «Engresca't a llegir (clubs de lectura joves)».

- Biblioteca Biblio@teneu (Sant Fost de Campsentelles). Iniciativa premiada: «Leemos, sentimos, nos emocionamos. Proyecto de integración social para personas con necesidades especiales».

- Biblioteca Municipal de Móra la Nova. Iniciativa premiada: "Llegeix, gaudeix, creix».

Cal destacar que Catalunya és un dels territoris amb menys participació al premi (6\%), per darrere de les Illes Balears i el País Basc.

El 2019 no hi ha hagut convocatòria.

- Premi Bones Pràctiques de lectura fàcil. S'ha atorgat el primer accèssit a la Biblioteca Joan Miró (Barcelona). Iniciativa premiada: Club de Lectura Fàcil amb usuaris de l'entitat TRACE (Associació Catalana de Traumàtics Cranioencefàlics i Dany Cerebral).

- Premi Teresa Rovira i Comas a la innovació a les biblioteques públiques. S'ha atorgat el premi a les biblioteques de Vilanova i la Geltrú. Iniciativa: premi Menjallibres. El 2019 no hi ha hagut convocatòria.

\subsection{Efemèrides i commemoracions}

Les biblioteques públiques empren cada cop més les efemèrides i les commemoracions proclamades per la Generalitat de Catalunya o per altres ens $i$ organismes per apropar als usuaris i usuàries l'obra dels autors $i$ autores homenatjats a través d'activitats, exposicions o guies de lectura.
Durant el període

2018-2019, s'atorguen pocs

premis a iniciatives de promoció de la lectura de les

biblioteques catalanes, a causa d'una baixa participació 
El 2018 va ser un any especialment important pel que fa a les efemèrides literàries. El Govern de la Generalitat va aprovar les commemoracions següents: l'Any Maria Aurèlia Capmany, per reivindicar el centenari del naixement de l'escriptora i el cent cinquantè aniversari del naixement del seu pare, el folklorista Aureli Capmany; l'Any Manuel de Pedrolo, per commemorar el centenari del naixement de l'escriptor; l'Any Montserrat Abelló, amb motiu dels cent anys del naixement de la poetessa; l'Any Carles Fages de Climent, en el cinquantè aniversari de la mort de l'autor empordanès, i l'Any Raimon Panikkar, filòsof i teòleg.

Dins les efemèrides del 2019, es va celebrar el centenari del naixement de l'escriptora i periodista Teresa Pàmies. També es van commemorar els cinquanta anys de la segona edició d'Aloma, la novel·la de Mercè Rodoreda. El 19 de gener va esdevenir l'Any Joan Brossa amb motiu de la commemoració del centenari del naixement del poeta barceloní. Una altra de les commemoracions internacionals molt celebrades va ser els cinc-cents anys de la mort de Leonardo da Vinci. Finalment, I'Assemblea General de les Nacions Unides (ONU) va proclamar el 2019 Any Internacional de la Taula Periòdica dels Elements Químics amb l'objectiu de celebrar la gènesi i el desenvolupament de la taula periòdica ara fa cent cinquanta anys.

\section{PUBLICACIONS}

Les publicacions principals editades a Catalunya o escrites per autors catalans vinculades amb la lectura i/o la seva promoció durant el període 2018-2019 són les següents:

- BiD: textos universitaris de biblioteconomia i documentació, vol. 42 (juny 2019), <http://bid.ub.edu/42>. [Consulta: 28-09-2020].

Número monogràfic dedicat a la prescripció lectora en què destaquen nombrosos articles d'iniciatives dutes a terme a les biblioteques públiques catalanes.

- Grup de Treball Passió per la Lectura; Centelles, Jaume (coord.) (2019). 99 invitacions a la lectura: activitats $i$ propostes per crear, compartir i gaudir amb els llibres. Barcelona: Associació de Mestres Rosa Sensat.

Dossier de propostes de promoció de la lectura als centres educatius que s'han dut a terme durant més de vint anys. Es presenten lectures des de diferents punts de vista per treballar-les amb els infants i els joves.

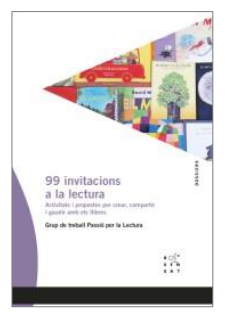
政

(a)

Les efemèrides i les commemoracions

són utilitzades per

les biblioteques

públiques per

apropar als usuaris i

usuàries l'obra dels

autors i autores

homenatjats a

través d'activitats, exposicions o guies de lectura 
- Lluch, Gemma (2018). La lectura: entre el paper i les pantalles. Vic: Eumo.

Assaig sobre la transformació del fet lector a partir de la irrupció d'internet. Reflexiona sobre les noves maneres de llegir, els hàbits de lectura entre els adolescents, la lectura i la identitat, els formats de la lectura, la promoció, la influència del llenguatge audiovisual, les xarxes socials, etc.

- Moncasí Salvia, Nati; Soto, Roberto (2018). "Les biblioteques mòbils: experiències de promoció de la lectura i transformació social». Faristol, núm. 87.

Desgrana diferents experiències a Portugal, la República Dominicana i Catalunya per apropar la biblioteca a entorns allunyats i garantir la cohesió social i la igualtat d'oportunitats entre tots els ciutadans, independentment del lloc de residència.

- Matamoros Ginabreda, Eva (coord.) (2018). \#Món jove: recomanacions per a fer lectors adolescents. Barcelona: Generalitat de Catalunya, Departament de Cultura, Direcció General de Cooperació Cultural, Servei de Biblioteques. $<$ https://biblioteques.gencat.cat/web/.content/tematic/profession als/bibliografies/bibliografies tematiques/documents/mon jove.pd f>. [Consulta: 28-09-2020].

Guia de lectures recomanades per a joves que s'estructura a través de cinc grans eixos: la identitat, l'estil de vida, les coses que fan, les relacions i les preocupacions.

- Ordas, Ana (2018). Gamificación en bibliotecas: el juego como inspiración. Barcelona: Universitat Oberta de Catalunya.

Manual de disseny de dinàmiques de joc per a activitats de promoció de la lectura i de l'ús de la biblioteca. També s'acompanya d'experiències reals.

- Peix, Susana; Almirall, Meritxell (2019). Lectura $i$ discapacitat: què, qui i com. Barcelona: Publicacions de l'Abadia de Montserrat.

La monografia aborda els elements clau per entendre la discapacitat i les necessitats lectores dels infants que en pateixen, per donar eines $i$ recursos per a la promoció de la lectura per al públic
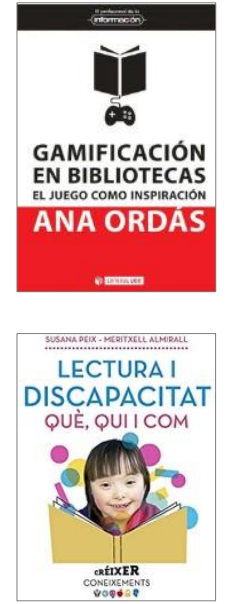

La transformació del fet lector a partir de la irrupció d'internet, les lectures recomanades per a joves o el disseny de dinàmiques de joc per a activitats de promoció de la lectura són alguns dels temes de les publicacions editades en aquest bienni infantil. 
- Portell Rifà, Joan; Ruiz Chacón, Gisela (2019). Adolescents i lectura: el binomi fantàstic lo com acostar, treballar i promocionar la lectura entre els joves). Barcelona: Publicacions de l'Abadia de Montserrat.

Assaig sobre l'adolescència, els hàbits lectors i els entorns de la lectura adolescent (l'escola, l'aula i els

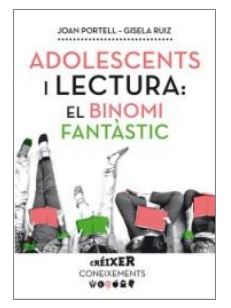
iguals). S'hi inclouen experiències en entorns bibliotecaris i una selecció de lectures per als adolescents.

- Salvador, Eugènia; Serra, Elisabet; Vidal, Laia (2019). «Associació Lectura Fàcil: 15 anys teixint complicitats i fent nous lectors». Item: revista de biblioteconomia i documentació, vol. 2019, núm. 67. $<$ https://www.raco.cat/index.php/Item/article/view/362827>.

[Consulta: 28-09-2020].

L'Associació de Lectura Fàcil recull les fites principals assolides en quinze anys d'existència, des de l'impuls de l'edició de llibres de lectura fàcil, passant per la promoció de la lectura com a eina d'inclusió social i una cronologia dels fets més destacats durant aquests anys.

- Trilla, Jordi (2018). "El perquè de \#llibrèfils». Item: revista de biblioteconomia i documentació, vol. 2, núm. 64. $<$ https://www.raco.cat/index.php/Item/article/view/341641>.

[Consulta: 28-09-2020].

L'article explica la campanya de difusió Llibrèfils que es va impulsar per difondre el Pla de lectura 2020 de la Generalitat de Catalunya.

\section{TENDÈNCIES}

En aquest bienni les biblioteques públiques han consolidat i augmentat el nombre d'activitats de foment de la lectura, fet que demostra que la promoció de l'hàbit i la competència lectora continuen sent l'essència i el motor d'aquests equipaments. Però la implementació d'un nou model bibliotecari basat en la innovació, amb serveis i activitats més enfocades a l'experimentació, la creació i la transferència de coneixements segurament comportarà nous usos i nous serveis.

En efecte, la biblioteca tendeix a convertir-se en el punt de trobada de la ciutadania no només amb la lectura, sinó amb el coneixement, i ofereix els espais bibliotecaris per facilitar la descoberta, l'aprenentatge, la creació i la connexió entre la comunitat. El projecte de Bibliolabs és segurament el màxim exponent d'aquesta nova concepció, que s'inspira en el model nòrdic de biblioteca pública i que pretén l'experiència a la biblioteca en aprenentatges vivencials significatius que permetin l'intercanvi del
Les biblioteques

públiques han

consolidat i

augmentat el

nombre d'activitats

de foment de la

lectura 
coneixement ciutadà, sovint poc reconegut com a experiència formativa, de creixement intel-lectual i de gaudi.

La irrupció de les narratives digitals a les biblioteques públiques també esdevindrà un nou repte per al foment de la lectura que se situa, no només en el text i la imatge, sinó també en el món del videojoc. La formació dels bibliotecaris i les estratègies de promoció d'aquesta tipologia de continguts marcaran, en part, el proper bienni.

\section{BIBLIOGRAFIA}

Diputació de Barcelona. Gerència de Servei de Biblioteques (2019). Memòria 2018. Barcelona: Diputació de Barcelona.

$<$ https://intrabib.diba.cat/xt/bib/documentacio/qui som/gerencia/memori es/memoria2018.pdf>. [Consulta: 28/09/2020].

Diputació de Barcelona. Gerència de Servei de Biblioteques (2020). Memòria 2019. Barcelona: Diputació de Barcelona.

<https://intrabib.diba.cat/xt/bib/documentacio/qui som/gerencia/memori es/memoria2019.pdf>. [Consulta: 28/09/2020].

Generalitat de Catalunya. Departament de Cultura (2020?). Memòria del Departament de Cultura 2019. [Barcelona]: Generalitat de Catalunya. $<$ https://drac.cultura.gencat.cat/bitstream/handle/20.500.12368/14490/D ADES ACTIVITAT 2019.DEF.agost.pdf>. [Consulta: 28/09/2020].

Generalitat de Catalunya. Departament de Cultura (2019?). Memòria del Departament de Cultura 2018. [Barcelona]: Generalitat de Catalunya.

<https://cultura.gencat.cat/web/.content/sscc/gt/arxius gt/DADES ACTIVI TAT 2018.pdf>. [12/10/2020].

Generalitat de Catalunya. Servei de Biblioteques (2018?). Arriben els bandolers (Projecte "Estiu a la biblioteca 2018»). [Barcelona]: Generalitat de Catalunya.

$<$ https://biblioteques.gencat.cat/ca/biblioteques/estructura organitzacio/s erveis suport bp/regionals/tarragona/activitats/projectescentral/arribenels-bandolers/>. [Consulta: 28/09/2020].

Generalitat de Catalunya. Servei de Biblioteques (2010-). Projectes $i$ experiències. [Barcelona]: Generalitat de Catalunya.

$<\underline{\text { https://biblioteques.gencat.cat/ca/biblioteques/estructura organitzacio/s }}$ erveis suport bp/regionals/lleida/biblioteques/Projectes i experiencies $>$.

[Consulta: 28/09/2020].
La irrupció de les

narratives digitals a

les biblioteques

públiques també

esdevindrà un nou

repte per al foment

de la lectura

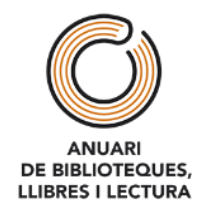


Generalitat de Catalunya. Servei de Biblioteques (2019?). Sistema de Lectura Pública de Catalunya: Balanç 2018. [Barcelona]: Generalitat de Catalunya.

$<$ https://biblioteques.gencat.cat/web/.content/tematic/biblioteques/dades -al-dia/estadistiques/balancos/documents/balanc 2018.pdf>. [Consultat: 28/09/2020].

Puig i Calafell, Marta (2019). "Submerllibres per perdre's al fons de la biblioteca». Bibliosfera, gener 2019, núm. 122.

$<$ https://www.diba.cat/biblioteques/bibliosfera//newsletter/45827296/122/226671117/submerllibres-per-perdre-s-al-fonsde-la-biblioteca>. [Consulta: 28/09/2020]. 
Disponible a:

https://revistes.ub.edu/index.php/Anuari-BLL/article/view/011

Ruiz Chacón, Gisela; Vazquez Puig, Elisabet. «La promoció de al lectura a les biblioteques públiques de Catalunya (2018-2019)». Anuari de Biblioteques, Llibres i Lectura, vol. 6 (2020), p. 200-218.

DOI 10.1344/ABLL.2020.6.011

Llicència Creative Commons

Reconeixement - NoComercial - SenseObraDerivada

(by-nc-nd): No es permet un ús comercial de l'obra

original ni la generació d'obres derivades.

\section{(c) (1) $(9$}




\title{
ANUARI
}

\section{DE BIBLIOTEQUES,}

\section{LLIBRES I LECTURA}

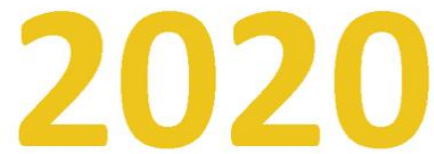

\section{Editors}

\author{
Lluís Agustí \\ Maite Comalat
}

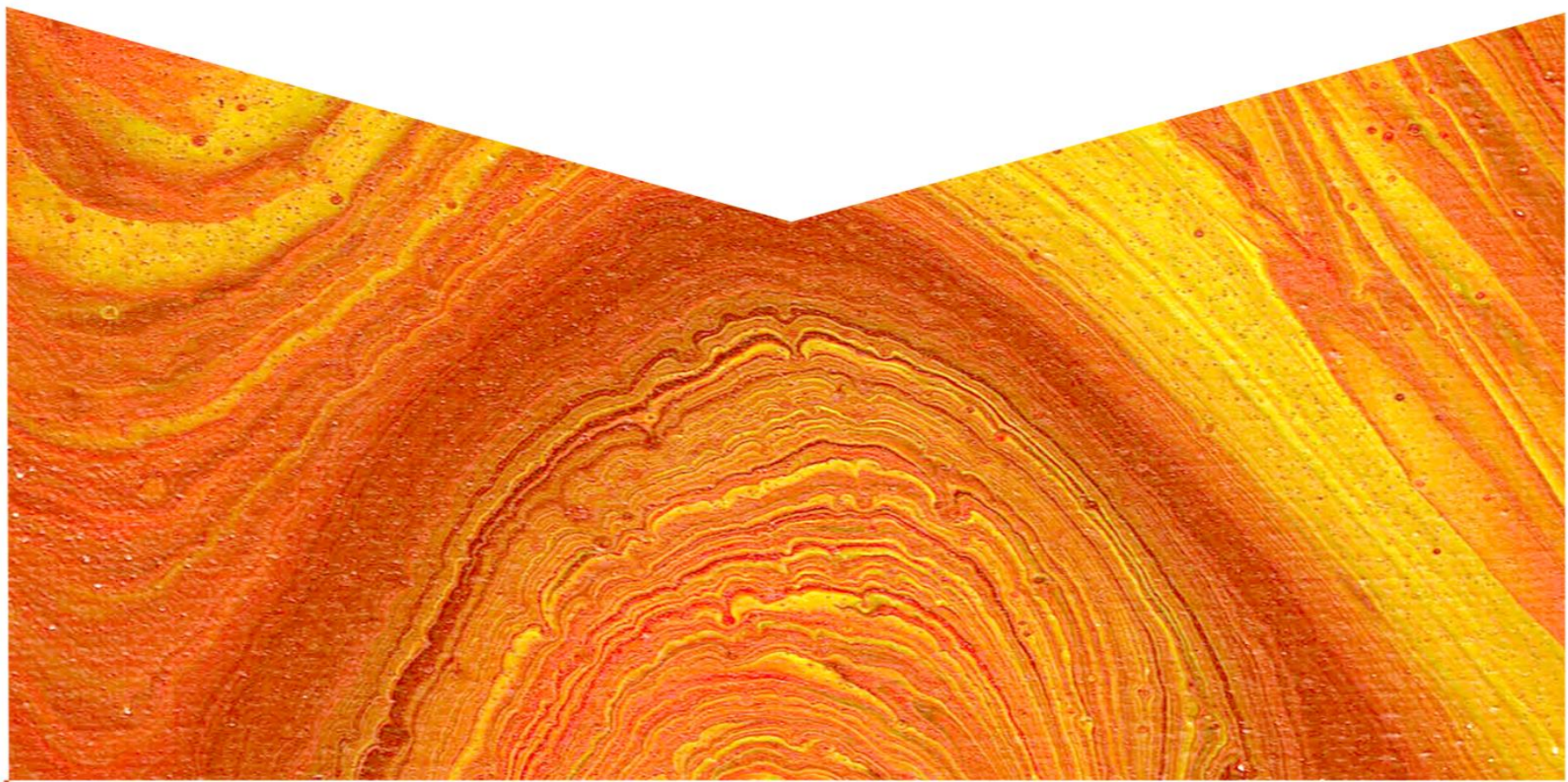

